\title{
Producer Soil Test Information Sheet
}

\section{Mailing Address (please print)}

Name

Address

City

FL Zip

Date

E-Mail *

Phone

\section{Note: This Lab Only Tests Samples from the State of Florida.}

Direct any questions regarding this test or the interpretation of the results to your county Extension Agent.

* In order to expedite reporting of results; please provide an e-mail address if possible.

Fill in all requested information, using one line per sample and additional sheets for more than 10 samples.

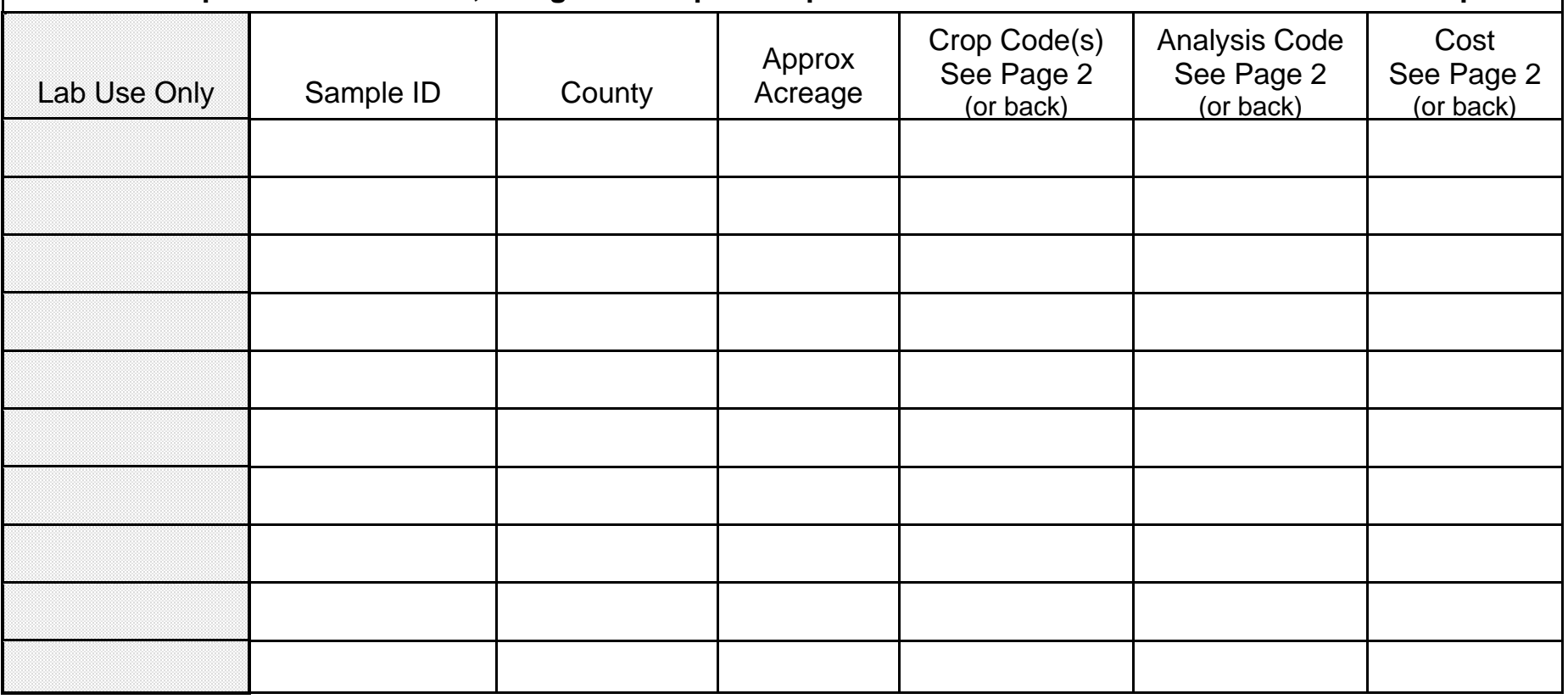

NOTE SPECIAL PROBLEMS HERE:

Check

Money Order

Cash

Total

SAMPLES WILL NOT BE PROCESSED WITHOUT PAYMENT.

Please enclose payment and this sheet in the same package as sample(s).

Do not send cash through the mail.

\section{Important Information for Sample Collection and Submission}

\section{Before Sampling:}

1. Develop a soil sampling plan of your field. Samples should represent the area being tested, so collect samples from areas that are of the same soil type, appearance, or cropping history. Sample problem areas separately, if needed. From this plan, count the number of samples you will collect.

2. Soil sample bags, addressed shipping boxes, and information sheets are available free from your county Cooperative Extension office. Obtain the materials you need to complete your sampling plan.

Collecting Samples:

1. Collect soil from 20 or more spots within each area, mixing these samples in a clean plastic bucket.

2. Sample from soil surface to depth of tillage, usually 0 to 6 inches. For pastures, sample from 0 to 4 inch depth.

3. Spread the composited material on clean paper or other suitable material to air dry. Do not send wet samples.

4. Mix the dry soil, and place about one pint of soil in a labeled sample bag.
Sending samples to the Extension Soil Testing Laboratory:

1. Enter each sample's identification on its sample bag and in the Soil Sample Identification" column. List each sample separately.

2. Lime and fertilizer recommendations are provided only if the crop code(s) is listed.

3. Include the analysis code for each desired test.

4. Enter costs from the Analysis Cost list found on page 2 of this form.

5. Sum the costs of all samples and analyses. Make check or money order payable to: University of Florida.

6. Include the completed Producer Soil Test Information Sheet and the check or money order in the shipping box with the sample(s).

Test results:

A soil test report will be emailed / mailed to you within 5 to 10 days after your sample arrives at the Extension Soil Testing Laboratory. Contact your county Extension office if you have questions concerning the Soil Test Report. 


\section{Crop and Analysis Codes for Producer Soil Test Information Sheet}

Standard fertilizer and lime recommendations based on your soiltest results will be supplied along with the test results if you indicate a crop code. Please write the appropriate crop codes on page 1 of this form. If your cropping situation is not in the list of codes below, routine soil tests may not be appropriate. In such instances, consult your local county agent before sending soil

Use special forms for requesting Landscape \& Vegetable Garden Soil Test (SL-136), the Container Media Test (SL134), or the Pine Nursery Soil Test (SL-132).

\section{AGRONOMIC CROPS}

\section{Crop Code Field Crops}

corn, nonirrigated

corn, irrigated

cotton

grain sorghum

oats for grain

peanuts

rye for grain

soybeans

sugarcane for syrup

tobacco (flue cured)

wheat for grain

Crop Code Pasture and Forage Crops

\section{3 alfalfa}

35 bahiagrass, establishment of new plantings (See Note)

26 cool season annual grasses (small grains and

$$
\text { ryegrass) }
$$

22 cool season legumes or legume-grass mixtures

(lupines, sweetclover, vetches and all true clovers

- white, red, arrowleaf, crimson, subterranean)

32 hay or silage (perennial grass)

25 improved perennial grasses other than bahiagrass

(bermuda, digit, star)

33 limpograss (Hemarthria)

28 perennial peanuts

14 summer forages (e.g., millet or sorghum)

21 warm season legumes or legume-grass mixtures

(aeschynomene, alyceclover, desmodium, hairy

indigo and other tropical legumes)

NOTE: Crop Code 35- Only analysis 1, 2, and 3 can be requested. Decisions concerning liming and $\mathrm{N}$ fertilization of bahiagrass pastures are very sensitive to cattle productivity and prices. samples for testing.

\section{VEGETABLE CROPS}

Please use the Landscape \& Vegetable Garden Test Information Sheet (SL-136) for home gardens. Codes for particular vegetables will result in fertilizer recommendations for commercial vegetable production which are not appropriate for home vegetable gardens.

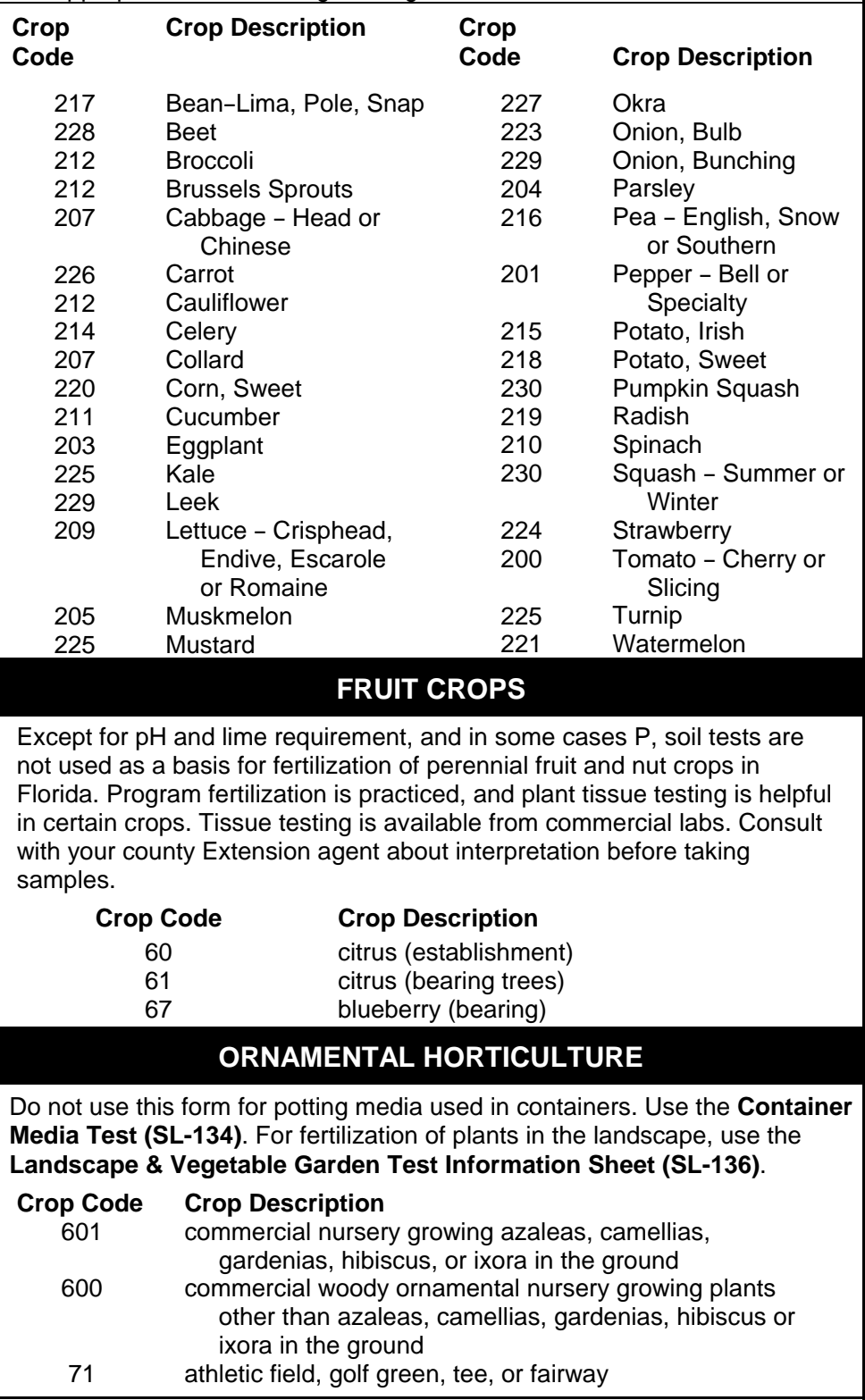

\begin{tabular}{|c|c|c|c|}
\hline Analysis Code & Analysis Name & Determinations Made & Analysis Cost \\
\hline 1 & Standard Soil Fertility Test & $\mathrm{pH}$, lime requirement, $\mathrm{P}, \mathrm{K}, \mathrm{Ca}$, and $\mathrm{Mg}$ & $\$ 7.00$ \\
\hline $2^{*}$ & Soil pH and Lime Requirement & $\mathrm{pH}$ and lime requirement & $\$ 3.00$ \\
\hline 3 & Soil Micronutrients & $\mathrm{Cu}, \mathrm{Mn}, \mathrm{Zn}$, and $\mathrm{pH}$ & $\$ 5.00$ \\
\hline 4 & Organic Matter & percent organic matter & $\$ 10.00$ \\
\hline 5 & Electrical Conductivity ("soluble salts") & conductivity in 1:2 soil:water & $\$ 2.00$ \\
\hline
\end{tabular}

